\title{
El enriquecimiento por intromisión en el derecho brasileño: propuesta de calificación como
}

enriquecimiento injustificado*

\section{Rodrigo da Guia Silva**}

RESUMEN. Este estudio se propone elaborar una propuesta de calificación dogmática del enriquecimiento por intromisión, en el derecho civil brasileño, a partir de la delimitación de las fronteras entre la responsabilidad civil y la prohibición del enriquecimiento injustificado. La premisa metodológica es el análisis funcional de las obligaciones y de los respectivos regímenes jurídicos obligacionales generales. A continuación se señalan algunas razones para la insuficiencia del intento de confrontación del enriquecimiento por intromisión a partir de la disciplina de la responsabilidad civil. Finalmente, se formula la propuesta de calificación del enriquecimiento por intromisión como modalidad de enriquecimiento injustificado.

Palabras Clave: enriquecimiento por intromisión, enriquecimiento injustificado, responsabilidad civil, fuentes de las obligaciones.

* Fecha de recepción: 7 de enero de 2020. Fecha de aceptación: 14 de agosto de 2020. Para citar el artículo: DA GUIA SiLVA, R. "El enriquecimiento por intromisión en el derecho brasileño: propuesta de calificación como enriquecimiento injustificado", Revista de Derecho Privado, Universidad Externado de Colombia, n. ${ }^{\circ}$ 40, enero-junio 2021, 311-327, Dor: https://doi.org/10.18601/01234366. n40.11.

Este trabajo corresponde, con numerosos ajustes y adiciones, a un subepígrafe de la tesis desarrollada en la maestría en Derecho Civil del período académico 2016-2017 ofrecido por la Universidade do Estado do Rio de Janeiro, Brasil.

** Instituto Brasileiro de Estudos de Responsabilidade Civil, Belo Horizonte, Brasil; miembro. Instituto Brasileiro de Direito Civil, Rio de Janeiro, Brasil; miembro. Instituto Brasileiro de Direito Contratual, São Paulo, Brasil; miembro. Magíster en Derecho Civil, Universidade do Estado do Rio de Janeiro, Rio de Janeiro, Brasil. Abogado, Universidade do Estado do Rio de Janeiro, Rio de Janeiro, Brasil. Contacto: rodrigo.daguiasilva@gmail.com Ordid: 0000-0001-6140-6459. 


\title{
A Proposal for the Qualification of Enrichment due to Interference under Brazilian Private Law: Revising the Boundaries Between Civil Liability and Unjustified Enrichment
}

\begin{abstract}
This study aims to develop a proposal for dogmatic qualification of enrichment due to interference, in Brazilian Private Law, based on the delimitation of the boundaries between civil liability and the prohibition of unjustified enrichment. The methodological premise is the functional analysis of the obligations and of the respective general legal regimes of obligations. The paper indicates some reasons for the insufficiency of the attempted confrontation of the enrichment due to interference from the discipline of civil liability. Finally, the study formulates the proposal for qualification of enrichment due to interference as a modality of unjustified enrichment.
\end{abstract}

KEYWORDS: enrichment due to interference, unjustified enrichment, civil liability, sources of obligations.

SUMARIO. Introducción: nociones preliminares sobre el enriquecimiento por intromisión. I. Premisa metodológica: el análisis funcional de las obligaciones en el derecho civil. II. Algunas razones para la insuficiencia del intento de confrontación del enriquecimiento por intromisión a partir de la disciplina de la responsabilidad civil. III. Propuesta: la calificación del enriquecimiento por intromisión como modalidad de enriquecimiento sin causa. Conclusión. Referencias.

\section{Introducción: nociones preliminares sobre el enriquecimiento por intromisión}

Antes de comenzar propiamente la confrontación del presente asunto -que está directamente relacionado con la definición de las fronteras entre responsabilidad civil y enriquecimiento sin causa- es necesario establecer premisas que permitan la comprensión adecuada de lo que viene a ser el enriquecimiento por intromisión. Algunos ejemplos pueden facilitar la comprensión de la materia. Inicialmente, se puede pensar en el uso no autorizado de la imagen ajena. Imagínese, en este sentido, que una cierta sociedad empresarial, para promover su nueva marca de cerveza, decide intentar contratar al cantante más famoso del país para protagonizar su campaña publicitaria. Supóngase, sin embargo, que el artista rechaza la propuesta. Disgustada por la respuesta negativa, la empresa publica fotografías del cantante en el centro de la campaña publicitaria, aludiendo a la supuesta preferencia del artista por la cerveza anunciada. En este caso, ¿tendría razón el artista al solicitar, además de la compensación de los daños morales y la reparación del lucro cesante (calculados sobre la base de lo que el artista cobra regularmente por campañas similares), 
también el pago de una parte de las ganancias obtenidas por la cervecería a de usar tu imagen ${ }^{1}$ ?

Otro ejemplo: imagínese que María, después de escuchar que su vecina Paula ha dejado el país por un año, ocupa la casa que pertenece a Paula y la usa para sus propios intereses privados. Además de vivir, María promueve varias fiestas y eventos en la casa, exigiendo siempre el pago de billetes para la entrada. En las semanas previas al regreso de la propietaria, María contrata a la mejor empresa de ingeniería de la ciudad para reparar todas y cada una de las partes de la casa que se han deteriorado durante su ocupación. Cuando Paula finalmente regresa, su casa está desocupada y no presenta ningún daño. Espontáneamente, María está dispuesta a pagar el monto correspondiente al alquiler de la casa durante ese período, sabiendo que ese monto sería mucho menor que todos los beneficios que obtuvo. En estas circunstancias, ¿tendría razón Paula para solicitar que se condene a María al pago de una parte de las ganancias obtenidas por las fiestas y eventos realizados en su casa?

A partir de estas preguntas se puede delinear una conceptualización preliminar del enriquecimiento por intromisión: se trata, esencialmente, de una ventaja patrimonial obtenida a partir de la explotación no autorizada de un bien o de un derecho ajeno $^{2}$. Entendido su concepto general, es preciso preguntar: ¿contiene el derecho brasileño algún instrumento para reprimir la obtención de ventaja injustificada en la forma del enriquecimiento por intromisión? Para responder a esta pregunta es necesario investigar si alguna norma de la legislación brasileña puede justificar la imposición de dicha obligación a la persona que ha obtenido el enriquecimiento por

1 Al considerar un caso similar -y paradigmático en el derecho brasileño-, el Superior Tribunal de Justicia respondió afirmativamente a la pregunta aquí enunciada, afirmando: “2. Acción de indemnización propuesta por una actriz por el uso no autorizado de su nombre e imagen en una campaña publicitaria. Solicitud de reparación de los daños morales y patrimoniales, además de la restitución de todos los beneficios económicos que la demandada obtuvo en la venta de sus productos. 3 . Además del deber de reparación por daños morales y materiales causados por el uso no autorizado de la imagen de una persona con fines económicos o comerciales, de conformidad con la Súmula n. 403/ STJ, el titular del bien jurídico infringido tiene derecho a exigirle al infractor reembolso del beneficio que obtuvo a su costa". sTJ, 3. . T., REsp 1.698.701/RJ, Min. Rel. Ricardo Villas Bôas Cueva, Sentencia 2/10/2018 (trad. libre del original). Para un análisis sobre la convivencia entre responsabilidad civil y prohibición de enriquecimiento injustificado en materia de protección a la privacidad, véase Amelung, U., Der Schutz der Privatheit im Zivilrecht: Schadenersatz und Gewinnabschöpfung bei Verletzung des Rechts auf Selbstbestimmung über personenbezogene Informationen im deutschen, englischen un US-amerikanischen Recht, Tübingen, Mohr Siebeck, 2002, passim.

2 Así conceptualiza, en el ámbito del sistema portugués, LeITÃo, L. M. T. M., O enriquecimento sem causa no direito civil: estudo dogmático sobre a viabilidade da configuração unitária do instituto, face à contraposição entre as diferentes categorias de enriquecimento sem causa, Lisboa, Centro de Estudos Fiscais, 1996, 688. La conceptualización preliminar presentada aquí parece permitir, al menos en principio, la configuración del enriquecimiento por intromisión en la hipótesis de la explotación no autorizada de bien o derecho de carácter no estrictamente individual. La resolución de tal situación de enriquecimiento por intromisión posiblemente requeriría la aplicación de los instrumentos provistos por el ordenamiento para la tutela de los derechos colectivos lato sensu (incluyendo los derechos individuales homogéneos, los derechos colectivos stricto sensu y los derechos difusos), de lo que podría resultar, por ejemplo, según corresponda, un reconocimiento de legitimidad activa extraordinaria y la asignación del monto de la sentencia a un fondo colectivo. 
intromisión. Teniendo en cuenta que no se perfeccionó un negocio jurídico (lo que podría justificar la aplicación de las reglas contractuales), la pregunta que surge es: ¿el enriquecimiento por intromisión es una cuestión de responsabilidad civil o de enriquecimiento injustificado? A esta pregunta el presente estudio se propone dar respuesta al final de las siguientes reflexiones, basadas en la metodología del derecho civil-constitucional, especialmente en cuanto al análisis funcional de las obligaciones y de los respectivos regímenes jurídicos obligacionales generales.

\section{Premisa metodológica: el análisis funcional de las obligaciones en el derecho civil}

El desarrollo contemporáneo de la teoría general de las obligaciones encuentra un desafío relevante en las hipótesis reunidas bajo la etiqueta genérica enriquecimiento por intromisión. Estas son, como hemos visto, situaciones en las que una persona en particular obtiene ventaja patrimonial de la explotación no autorizada de bienes o de derechos ajenos. Tal ventaja patrimonial puede asumir cualquiera de las configuraciones típicas de enriquecimiento (aumento de activos, disminución de pasivos o ahorro de gastos). La doctrina ha buscado construir una especie de régimen jurídico general para el enriquecimiento por intromisión, enfocándose especialmente en la identificación del fundamento para su eventual restitución y en la cuantificación de la obligación restitutoria que se impone al interventor ${ }^{3}$.

Un caso que siempre se recuerda en relación con el enriquecimiento por intromisión es el juzgado, en la experiencia portuguesa, por el Supremo Tribunal de Justicia en la sentencia del 3 de abril de 1964: el propietario de un terreno ribereño, ubicado a la orilla del río Dão, se dio cuenta de que los propietarios de la tierra contigua retiraron doscientos cinco pies de aliso (árbol típico de la región) y quinientos camiones de arena, por lo que presentó una acción para obtener la indemnización de los daños con fundamento en la responsabilidad civil. En defensa, los propietarios del terreno vecino invocaron, entre otros argumentos, que la acción natural del río Dão ya había restaurado la cantidad original de arena del terreno. Este argumento fue confirmado por el Supremo Tribunal de Justicia, que consideró que solo en relación con el corte de los alisos sería posible reconocer los daños indemnizables. Con respecto a la arena removida por los interventores, el Tribunal concluyó que la restauración natural del banco de arena impedía la fijación de los daños reparables, por lo que el propietario tendría que incoar otra acción basada específicamente en el enriquecimiento injustificado (en la modalidad de intromisión) de los vecinos interventores ${ }^{4}$.

3 Para un análisis de las dificultades inherentes al esfuerzo de encuadre dogmático de las hipótesis de enriquecimiento por intromisión en el derecho brasileño, véase KONDER, C. N., "Dificuldades de uma abordagem unitária do lucro da intervenção", Revista de Direito Civil Contemporâneo, vol. 13, octubre-diciembre, 2017, passim.

4 Este relato se remonta a la lección de LEITÃo, L. M. T. M., O enriquecimento sem causa no direito civil, cit., 717. 
Por cierto, este artículo no es el lugar adecuado para el desarrollo de todas las preguntas planteadas por la doctrina con respecto a las reglas del enriquecimiento por intromisión. Solo se pretende aquí abordar algunas posibles consecuencias derivadas de la calificación funcional de las obligaciones en el derecho civil, con énfasis particular en el análisis funcional de las obligaciones vinculadas a la prohibición del enriquecimiento sin causa. La percepción de similitudes y distinciones funcionales entre los diferentes tipos de obligaciones permite la aplicación de la normativa que esté más directamente relacionada con la obligación específica que enfrenta el intérprete, a fin de lograr la satisfacción de los intereses merecedores de tutela que están en juego en cada hipótesis ${ }^{5}$. De hecho, en materia obligacional, el interés del acreedor $^{6}$-a ser tutelado de acuerdo con el régimen jurídico respectivo- puede ser susceptible de reconducción, dependiendo de la hipótesis fáctica que originó la obligación, del cumplimiento de las expectativas derivadas de los compromisos asumidos, de la reparación de daños causados o de la reversión de transferencias patrimoniales injustificadas ${ }^{7}$.

Sustancialmente, el análisis funcional de las categorías de obligaciones tratadas en el derecho brasileño hace posible su sistematización en torno a tres regímenes principales (negocial, reparatorio y restitutorio), vinculados a la fuente de la respectiva obligación: negocio jurídico, daño injusto y enriquecimiento injustificado ${ }^{8}$. Se debe reconocer, por lo tanto, una tripartición funcional de obligaciones, pudiéndose separar las funciones ejecutoria (de un negocio legítimamente celebrado) ${ }^{9}$, repa-

5 Resaltando la relevancia del estudio de las fuentes de obligaciones para la definición del régimen jurídico aplicable, véase BARASSI, L., La teoria generale delle obbligazioni, tomo II, 2. a ed., Milano, Giuffrè, 1964,p. 1.

6 Las cifras de acreedores y deudores se mencionan por la consagración de su uso en la práctica brasileña, sin perjuicio de la premisa metodológica según la cual toda relación jurídica (incluida la obligacional) consiste, desde el punto de vista subjetivo, en un vínculo entre centros de interés (en este sentido véase, por todos, Perlingieri, P., O direito civil na legalidade constitucional, M. Cristina De Cicco [trad.], Rio de Janeiro, Renovar, 2008, 734 y ss.), e igualmente sin perjuicio de la premisa metodológica de acuerdo con cual la complejidad de la relación obligacional apunta a la multiplicidad de situaciones jurídicas subjetivas activas y pasivas vinculadas a cada uno de los centros de interés (en este sentido véase, por todos, Larenz, K., Derecho de obligaciones, t. I, J. Santos Briz [trad.], Madrid, Revista de Derecho Privado, 1958, 37). Para un análisis más detallado de las influencias de estas premisas metodológicas en la comprensión del fenómeno obligacional, véase SiLVA, R. G. "Novas perspectivas da exceção de contrato não cumprido: repercussões da boa-fé objetiva sobre o sinalagma contratual", Revista de Direito Privado, año 18, n. ${ }^{\circ} 78,2017,48$ ss. Pertinente, aun sobre las influencias de la complejidad de las relaciones contemporáneas -específicamente en cuanto a la configuración del deber de información-, el análisis de Chinchilla Imbett, C. A., "El deber de información contractual y sus límites", Revista de Derecho Privado, Universidad Externado de Colombia, n. ${ }^{\circ} 21,2011,328$ ss

7 En este sentido, véase Noronha, F., Direito das obrigações, 4. a ed., São Paulo, Saraiva, 2013, 440.

8 Véase Espínola, E., Garantia e extinção das obrigações: obrigações solidárias e indivisíveis, GALVÃo BRuno, F. J. (actualización), Campinas, Bookseller, 2005, 75-77.

9 La función ejecutoria es caracterizada por la promoción del contrato (o del negocio jurídico unilateral) según lo fijado por la voluntad individual. En cuanto a la relevancia del consentimiento para la configuración del contrato, la doctrina aclara: "El análisis de la tradición civil enseña que el contrato 
ratoria (de un daño injustamente causado) y restitutoria (de riqueza injustamente obtenida $)^{10}$. Por supuesto, un negocio jurídico puede prever obligaciones de restituir, más comúnmente conocidas como obligaciones de restituir (o devolver) cosa cierta. La restitución relevante para el presente estudio, por otro lado, es aquella dirigida funcionalmente no a promover un interés ajustado por contrato, sino a recomponer un patrimonio injustificadamente beneficiado.

El esfuerzo de sistematización apenas realizado nos permite concluir que la identificación del régimen jurídico que rige una determinada relación obligacional ( conjunto aplicable a cada caso concreto) depende de la vinculación funcional de la hipótesis específica a los regímenes fundamentales consagrados en el derecho brasileño -los regímenes negocial, indemnizatorio y restitutorio-. Por lo tanto, no es suficiente que la atención del intérprete se centre en la enunciación formal de las posibles fuentes de obligaciones, ya que cada hecho legal es teóricamente capaz de constituir, modificar o extinguir relaciones legales obligacionales, dependiendo de la valoración atribuida por el ordenamiento ${ }^{11}$. Por lo tanto, la polisemia de la expresión "fuentes de las obligaciones" no debe oscurecer la percepción de que cualquier hecho jurídico puede corresponder a una fuente obligacional (en el sentido de la hipótesis fáctica de la incidencia de la norma) y hacer aplicable, de acuerdo con la función específicamente realizada, los regímenes negocial, reparatorio y restitutorio.

En resumen, lo que parece ser más importante en este asunto es la investigación del papel que juega cada obligación específica. La premisa antes mencionada de

genera un vínculo entre las partes, que debe ser respetado por ellas tal como lo ordena el principio general de la buena fe, lo que significa, en principio, que ni podrán evitarse los efectos propios del tipo contractual, ni terminarse con el vínculo que los sujeta o modificarse el contenido contractual unilateralmente”. Chinchilla ImBeTt, C. A., “CContrarius consensus': terminación del contrato por mutuo acuerdo en la experiencia jurídica romana", Revista de Derecho Privado, Universidad Externado de Colombia, n. ${ }^{\circ}$ 28, 2015, 80-81. Asimismo, véase Hinestrosa, F., "Notas sobre la responsabilidad por incumplimiento de las obligaciones", Revista de Derecho Privado, Universidad Externado de Colombia, n. ${ }^{\circ} 36,2019,6$.

10 Esta formulación se remonta a Noronha, F., Direito das obrigações, cit., 439; y Miragem, B., "Pretensão de repetição de indébito do consumidor e sua inserção nas categorias gerais do direito privado: comentário à Súmula 322 do sTJ", Revista de Direito do Consumidor, vol. 79, julio-septiembre, 2011, 385. En un sentido similar en cuanto a la diferenciación entre obligaciones indemnizatorias y obligaciones restitutorias, véase, en la doctrina chilena, Pinochet Olave, R. y Concha Machuca, R., "Las prestaciones mutuas en caso de nulidad de contrato: carácter indemnizatorio o restitutorio en el derecho civil chileno", Revista de Derecho Privado, Universidad Externado de Colombia, n. ${ }^{\circ}$ 28, 2015, passim. También sobre la cuestión de las obligaciones restitutorias en caso de invalidez negocial, véase Concha, R., "Nulidad y obligaciones naturales: la obligación de restituir contra el derecho a retener en el código civil de Bello", Revista de Derecho Privado, Universidad Externado de Colombia, n. ${ }^{\circ}$ 26, 2014, passim; y Uribe, R. M. y Wilson, C. P., "Las restituciones consecutivas a la nulidad o resolución en los contratos de bienes muebles", Ius et Praxis, año 24, n. ${ }^{\circ}$ 1, 2018, passim. La relevancia de esta cuestión es señalada también por D’ANGELO, A., "Sentido actual y condiciones de uso de la disciplina general de las obligaciones", Revista de Derecho Privado, Universidad Externado de Colombia, n. ${ }^{\circ}$ 20, 2011, 256.

11 Véase Noronha, F., Direito das obrigações, cit., 367-368. 
análisis funcional de las obligaciones del derecho civil tendrá un impacto directo en la comprensión de la disciplina del enriquecimiento por intromisión en el sistema brasileño. Se destacan tres repercusiones principales de la mencionada premisa metodológica: (i) la definición del marco jurídico del enriquecimiento por intromisión en el derecho brasileño; (ii) la investigación sobre la posibilidad de acumulación de pretensiones con respecto al beneficio obtenido por el interventor y el daño sufrido por el titular del derecho, y (iii) la fijación de posibles criterios de cuantificación que parezcan compatibles con el marco legal del enriquecimiento por intromisión. Teniendo en cuenta la brevedad de este trabajo, el presente estudio se limita al análisis de la primera cuestión planteada ${ }^{12}$.

\section{Algunas razones para la insuficiencia del intento de confrontación del enriquecimiento por intromisión a partir de la disciplina de la responsabilidad civil}

Reconocidas las tres posibles categorías de obligaciones de acuerdo con las funciones desempeñadas, es importante investigar con cuál de ellas se relaciona más propiamente el enriquecimiento por intromisión. En principio, el enriquecimiento por intromisión se aleja de las obligaciones de fuente negocial, ya que la materia tiene como presupuesto lógico la intromisión no autorizada (es decir, sin ningún vínculo causal con negocio jurídico previo) en bienes o en derechos ajenos. La indagación debe proseguirse entonces respecto de las categorías vinculadas a la responsabilidad civil (reparación de daños injustos) y la prohibición del enriquecimiento sin causa, alrededor de las cuales existe una división doctrinal.

Por un lado, se sostiene que la intervención en bien o en derecho ajeno genera un daño indemnizable, cuyo monto debería ser integrado por el beneficio obtenido ilegítimamente por el interventor ${ }^{13}$. A partir de tal concepción, la responsabilidad civil surgiría como el mecanismo adecuado para la recuperación del beneficio obtenido por aquellos que explotaron sin autorización el bien o el derecho ajeno ${ }^{14}$. También se

12 Para el desarrollo de las demás cuestiones, véase SILVA, R. G., Enriquecimento sem causa: as obrigações restitutórias no direito civil, São Paulo, Thomson Reuters Brasil, 2018, 3.4; y SchreIBER, A. y SiLvA, R. G., "Aspectos relevantes para a sistematização do lucro da intervenção no direito brasileiro", Pensar, vol. 23, n. ${ }^{\circ}$ 4, 2018, passim.

13 Véase, por todos, en la doctrina brasileña, Rosenvald, N., A responsabilidade civil pelo ilícito lucrativo: o disgorgement e a indenização restitutória, Salvador, JusPodivm, 2019, passim; y RosenvaLD, N., "As fronteiras entre a restituição do lucro ilícito e o enriquecimento por intromissão", Revista de Direito da Responsabilidade, año 1, 2019, passim.

14 No es casualidad que se haya identificado que la propuesta de un marco para el enriquecimiento por intromisión en el ámbito de la responsabilidad civil tiende a ir acompañada de la expansión de las funciones de dicho instituto más allá de la función reparatoria básica, como se puede ver en Coelho, F. M. P., O enriquecimento e o dano, Coimbra, Almedina, 1970, 33. Para un desarrollo del análisis sobre algunas proposiciones contemporáneas sobre el sentido de la reparación integral, véase SANDOVAL, D., "Reparación integral y responsabilidad civil: el concepto de reparación integral y su vigencia en los daños extrapatrimoniales a la persona como garantía de los derechos de las 
afirma, en esta línea, que la consideración de las ventajas obtenidas por el autor de la mala conducta reflejaría un tercer método para calcular el daño patrimonial, junto con los criterios tradicionales del daño (o empobrecimiento) real y del patrimonial ${ }^{15}$.

Tal línea de entendimiento, que enmarca el enriquecimiento por intromisión en el ámbito de la responsabilidad civil, parece reflejarse directamente en la redacción del numeral II del artículo 210 de la Ley de Propiedad Industrial brasileña (Ley n. ${ }^{\circ}$ $9.279 / 1996)^{16}$. Dicha disposición establece para la determinación del lucro cesante, entre otros criterios, el de los "beneficios obtenidos por el autor de la violación del derecho" (trad. libre). Así, se observa, en al menos una hipótesis, la consagración normativa expresa de la proposición teórica que identifica la relevancia del beneficio obtenido por el interventor para la delimitación de la indemnización a ser pagada a favor de la víctima de un daño injusto.

Tal opción legislativa podría ser interpretada simplemente como un error normativo, pero debe tenerse en cuenta que la solución adoptada por la legislación nacional en el ámbito de la disciplina de las hipótesis de violaciones de los derechos de propiedad industrial no refleja una auténtica peculiaridad de la experiencia brasileña. De hecho, parece posible resaltar cierta similitud con las experiencias española ${ }^{17}$ y alemana ${ }^{18}$, en las cuales también se verifica una incorporación del criterio que se refiere al enriquecimiento del interventor en la disciplina propia de la responsabilidad civil. Tal es la influencia de la línea de entendimiento en el campo de la propiedad industrial e intelectual que la doctrina, en Brasil y en otros lugares, considera con

víctimas", Revista de Derecho Privado, Universidad Externado de Colombia, n. ${ }^{\circ}$ 25, 2013, passim. Pertinente, en cuanto a este punto, la lección de F. Hinestrosa: "Por más que se encarece y repite que la responsabilidad civil tiene un alcance exclusivamente resarcitorio: se debe indemnizar el daño causado, todo el daño causado y nada más que el daño causado, el binario ‘crimen y castigo' se mantiene presente, y en la condena a la reparación, individual y colectivamente, se continúa viendo una sanción, se sigue hablando del valor moralizador: de punición, a la vez que de la prevención (escarmiento) inherente a dicha condena, se ata el daño moral a la descalificación moral de la conducta del 'infractor', y se mira con codicia la figura de los punitive damages en el predio vecino del common law". Hinestrosa, F., "Devenir del derecho de daños", Revista de Derecho Privado, Universidad Externado de Colombia, n. ${ }^{\circ}$ 32, 2017, 10.

15 Véase Coelho, F. M. P., O enriquecimento e o dano, cit., 32, nota 53.

16 Ley de Propiedad Industrial brasileña (Ley n. 9.279 de 1996): "Art. 210. Los lucros cesantes se determinarán según el criterio más favorable para el perjudicado, entre los siguientes: [...] II - los beneficios que obtuvo el autor de la violación del derecho..." (trad. libre del original: "Art. 210. Os lucros cessantes serão determinados pelo critério mais favorável ao prejudicado, dentre os seguintes: [...] II - os benefícios que foram auferidos pelo autor da violação do direito...”).

17 Por cierto, debe destacarse la similitud entre el referido artículo 210 de la Ley de Propiedad Industrial de Brasil y el artículo 140 de la Ley de Propiedad Intelectual de España. Para un análisis detallado de la legislación española sobre propiedad intelectual, marcas y patentes, señalando cierta confusión entre los criterios de responsabilidad y de enriquecimiento sin causa, véase DíEz-PicAzo, L., Derecho de daños, Madrid, Civitas, 1999, 54 ss.

18 Pertinente, al respecto, es el relato de LeITÃo, L. M. T. M., O enriquecimento sem causa no direito civil, cit., 720-721. Para un relato de la experiencia alemana en la materia véase, también, FERREIRA, M. T. T. R., A tutela dos direitos de propriedade industrial pelo enriquecimento sem causa, tesis de máster, Universidad de Lisboa, Lisboa, 2013, 28-32. 
no poca frecuencia consistente en la exportación del criterio legal específico para cuantificar el lucro cesante en el área de la competencia desleal ${ }^{19}$. Al respecto, se cuestiona si es factible imponer al agente económico la obligación de restituir (total o parcialmente) el beneficio que ha obtenido a partir de la práctica de actos de competencia desleal $^{20}$.

A pesar del posible éxito en términos pragmáticos, la propuesta de resolución de la cuestión del enriquecimiento por intromisión en el área de responsabilidad civil parece provenir, en lo que más directamente importa para el presente estudio, de cierta resistencia a la promoción del análisis funcional para la calificación de obligaciones en el derecho civil. De hecho, puesto que la distinción funcional de las obligaciones (y de los respectivos regímenes jurídicos) se basa en el perfil funcional promovido en cada caso, se puede observar una cierta imprecisión conceptual en la inclusión de las ventajas obtenidas por el interventor en el proceso de cuantificación de la indemnización debida a la víctima de un daño injusto, como es el caso en el artículo 210, numeral II, de la Ley de Propiedad Industrial brasileña ${ }^{21}$. Se reconoce, en resumen, que la "pretensión de ganancias de la intervención y la pretensión indemnizatoria son [...] cosas fundamentalmente diferentes"22.

\section{Propuesta: la calificación del enriquecimiento por intromisión como modalidad de enriquecimiento sin causa}

En este punto, en un esfuerzo por comprender el marco teórico del enriquecimiento por intromisión, debemos estudiar la propuesta teórica de la aplicación del enriquecimiento injustificado. Contrariamente a la opinión que califica el enriquecimiento por intromisión como un daño indemnizable, se sostiene que la imposición de su restitución reflejaría, desde un punto de vista funcional, la preocupación por restaurar el patrimonio del interventor al estado en el que se encontraría si no se hubiera verificado el hecho generador del enriquecimiento ${ }^{23}$.

19 Véase Michelon JR., C., Direito restituitório: enriquecimento sem causa, pagamento indevido, gestão de negócios, São Paulo, Revista dos Tribunais, 2007, 202. Para un relato de la experiencia italiana en la materia, véase Giannotte, C., "Arricchimento senza causa”, en Cendon, P. (ed.), Trattato di diritto civile: titoli di credito, gestione di affari, ripetizione di indebito, arricchimento, Milano, Giuffrè, 2014, 620-621.

20 Se tiende a encontrar respuesta afirmativa sobre todo en las hipótesis de "competencia por explotación”. Michelon JR., C., Direito restituitório, cit., 202-203. En sentido semejante véase, en la doctrina portuguesa, LeITÃo, L. M. T. M., O enriquecimento sem causa no direito civil, cit., 759-760.

21 Véase Michelon JR., C., Direito restituitório, cit., 201-202.

22 Trad. libre del original: "Der Anspruch auf den Eingriffserwerb und der Schadenersatzanspruch sind [...] grundverschiedene Dinge". Schulz, F., "System der Rechte auf den Eingriffserwerb", Archiv für die civilistische Praxis, vol. 105, t. 1, 1909, 457. En cuanto a la distinción entre reclamos de indemnización (Schadenersatzansprüche) y reclamos de restitución (restitutorische Ansprüche), véase Busse, D., Internationales Bereicherungsrecht, Tübingen, Mohr Siebeck, 1998, 41 y ss.

23 Véase, por todos, Díez-Picazo, L., Derecho de daños, cit., 50. 
La propuesta de enmarcar el enriquecimiento por intromisión en el ámbito del enriquecimiento sin causa fue el foco de la doctrina especializada en la controversia sobre la posibilidad o no del tratamiento unitario del instituto ${ }^{24}$. Parte de la doctrina apoya la necesidad de la división del tema, argumentando la imposibilidad de reconducción de las variadas hipótesis de restitución a un fenómeno unitario ${ }^{25}$. Por lo tanto, se formuló una bipartición fundamental entre el enriquecimiento obtenido a partir de una prestación de los "empobrecidos" y el enriquecimiento obtenido de otras formas, incluido el enriquecimiento por intromisión en esta segunda categoría ${ }^{26}$. Esta forma de entender el fenómeno de la restitución parece manifestarse, en la doctrina contemporánea, en las propuestas teóricas que apuntan a la supuesta ausencia de fundamento común y, sobre todo, a la ausencia de similitud entre las disciplinas normativas derivadas de la cláusula general de restitución por enriquecimiento sin causa contenida en el artículo 884 c.c. brasileño ${ }^{27}$ y el reglamento de los institutos específicos como la gestión empresarial y el pago indebido, también animados por la función restitutoria.

Otra parte de la doctrina defiende la configuración unitaria del instituto del enriquecimiento sin causa, argumentando que las diversas hipótesis de restitución, aunque no sean idénticas en su eventual disciplina normativa, podrían reconducirse a principios comunes ${ }^{28}$. El desarrollo de tal línea de comprensión se debe en gran parte a los estudios de Fritz Schulz ${ }^{29}$, que intentó identificar en la violación de un derecho

24 Pertinente, en cuanto a este punto, el análisis de Geldres CAmpos, R., "El enriquecimiento injustificado por intromisión en el derecho ajeno", Gaceta Civil \& Procesal Civil, n. . 54, 2017, 157 y ss.

25 Resaltamos en este sentido la propuesta pandectista de la división del instituto de enriquecimiento sin causa, véase LeITÃo, L. M. T. M., O enriquecimento sem causa no direito civil, 342.

26 La concepción de división del instituto, con origen en la padectística, fue vigorosamente reanudada por Walter Wilburg y Ernst von Caemmerer, véase LeITão, L. M. T. M., O enriquecimento sem causa no direito civil, cit., 411. Todavía sobre la experiencia alemana, resulta pertinente la obra de Gomes, J. M. V., O conceito de enriquecimento, o enriquecimento forçado e os vários paradigmas do enriquecimento sem causa, Porto, Universidade Católica Portuguesa, 1998, 197.

27 "Cualquiera que, sin justa causa, se enriquezca a expensas de otra persona, estará obligado a devolver lo ganado injustificadamente, hecha la actualización de los valores monetarios..." (trad. libre del original: “Art. 884. Aquele que, sem justa causa, se enriquecer à custa de outrem, será obrigado a restituir o indevidamente auferido, feita a atualização dos valores monetários...”).

28 Para un relato sobre la propuesta doctrinal alemana de una configuración unitaria de enriquecimiento sin causa, en oposición a las propuestas de división del instituto, véase LEITÃo, L. M. T. M., O enriquecimento sem causa no direito civil, cit., 431-432. También respecto de la propuesta de reconocimiento de la unidad del instituto, véase entre otros, ÁlvAREZ-CAPEROCHIPI, J. A., El enriquecimiento sin causa, Madrid, Universidad de Santiago de Compostela, 1979, 71 y ss.

29 En cuanto a la importancia del trabajo de Fritz Schulz para la reformulación de la doctrina unitaria tradicional de enriquecimiento sin causa mediante su aplicación al problema del enriquecimiento por intromisión, véase LeITÃo, L. M. T. M., O enriquecimento sem causa no direito civil, cit., 402403. Vale la pena señalar que, de acuerdo con la formulación de Schulz, se debería reconocer la posibilidad de elección, por el acreedor, entre la pretensión de indemnización y la pretensión restitutoria (Schulz, F., "System der Rechte auf den Eingriffserwerb", cit., 457). Pertinente al respecto es el relato de Gomes, J. M. V., O conceito de enriquecimento, o enriquecimento forçado e os vários paradigmas do enriquecimento sem causa, cit., 183. 
ajeno la razón común de la puesta en marcha del mecanismo de restitución en sus diversas manifestaciones, independientemente de si implica o no una prestación de aquel a expensas de quien se ha enriquecido ${ }^{30}$. Aun a partir de la referida premisa teórica de la configuración unitaria del enriquecimiento sin causa, se desarrolló la idea de que el fundamento unificador del instituto no radicaría en la violación de un derecho ajeno (una circunstancia común y probable, pero no necesaria para la configuración del enriquecimiento sin causa), sino más bien en la doctrina del contenido de la atribución (Zuweisungsgehaltlehre) ${ }^{31}$. Se debería reconocer enriquecimiento sin causa, según tal formulación, cuando la incidencia del mecanismo restitutorio tuviera por objetivo principal garantizar la adecuada variación patrimonial según la destinación jurídica de los bienes ${ }^{32}$.

A pesar de los méritos de cada una de las proposiciones teóricas que pretendían dilucidar la configuración unitaria o fraccionada del instituto del enriquecimiento sin causa, una solución quizás más segura, a la luz de la metodología civil-constitucional, puede ser proporcionada por la propuesta de análisis de las obligaciones en el derecho civil mencionada anteriormente. Las relaciones obligacionales parecen ser susceptibles de reconducción a los regímenes jurídicos generales de acuerdo con la función desempeñada por cada tipo de obligación. Sobre la base de esta premisa metodológica, se enunció la tripartición de las obligaciones de acuerdo con los perfiles funcionales más comunes identificados: ejecutorio, reparatorio y restitutorio. A partir de estas premisas, se justifica el reconocimiento de la configuración unitaria del instituto del enriquecimiento sin causa en torno a la identidad del perfil funcional restitutorio de las variadas obligaciones de restitución (derivadas o no de la cláusula general del deber de restituir), para justificar, como ya se señaló, la incidencia del tratamiento uniforme y sistemático, aunque no necesariamente idéntico.

Las consideraciones anteriores permiten, en fin, aclarar el marco jurídico apropiado del enriquecimiento por intromisión en el derecho brasileño. Trátase de una forma de enriquecimiento sin causa, caracterizada por la explotación no autorizada de un bien o un derecho ajeno ${ }^{33}$. Tal es su relevancia en la conformación dogmática

30 Un resumen del terreno común sobre el cual Fritz Schulz pretendía justificar la configuración unitaria de enriquecimiento sin causa puede verse en LEITÃo, L. M. T. M., O enriquecimento sem causa no direito civil, cit., 407. También es relevante la reconstrucción de la teoría de Schulz específicamente sobre el enriquecimiento por intromisión realizada por GoMEs, J. M. V., O conceito de enriquecimento, o enriquecimento forçado e os vários paradigmas do enriquecimento sem causa, cit., 180-181.

31 En ese sentido, véase Barbosa, M. M., "Reflexões em torno da responsabilidade civil: teleologia e teleonomologia em debate", Boletim da Faculdade de Direito de Coimbra, vol. 81, 2005, 589-591.

32 Para una crítica a la supuesta insuficiencia de la teoría de Schulz debido a la tutela excesiva e injustificadamente atribuida al titular del derecho con base en una interpretación irrazonable de la doctrina del contenido de la atribución, véase KONDER, C. N. y SAAR, P., "A relativização do duplo limite e da subsidiariedade nas ações por enriquecimento sem causa”, en TePedino, G., Teixeira, A. C. B. y ALMEIDA, V. (coords.), Da dogmática à efetividade do direito civil: Anais do Congresso Internacional de Direito Civil Constitucional - IV Congresso do IBDCivil, Belo Horizonte, Fórum, 2017, 149-150.

33 Exactamente en este sentido se aprobó, en la vIII Jornada de Derecho Civil promovida por el Consejo de la Justicia Federal, la Declaración 620, in verbis: "La obligación de restituir el enriquecimiento 
del instituto que, a pesar de la comprensión previamente establecida de su configuración unitaria, se señalan dos modalidades fundamentales de enriquecimiento sin causa: enriquecimiento por prestación y enriquecimiento por intervención. La restituibilidad del enriquecimiento por intromisión dependerá, pues, o bien de una disposición específica para la restitución o bien de la cláusula general del deber de restituir. Suponiendo que no exista una disposición expresa (al menos en términos generales) capaz de cubrir las hipótesis de enriquecimiento por intromisión -lo que refleja el respeto a la norma de subsidiariedad contenida en el artículo 886 c.c. brasileño-, su restitución dependerá de la concreta declaración de los otros supuestos (in casu, los aspectos positivos) de la cláusula general contenida en el artículo 884 c.c. ${ }^{34}$.

El enriquecimiento del interventor, en el sentido de una ventaja patrimonial efectiva (y no virtual o hipotética), podrá consistir, de acuerdo con la comprensión general esbozada en la doctrina, en aumento de los activos, disminución de los pasivos o ahorro de gastos, modalidades a las que parecen ser pasibles de reconducción las hipótesis fácticas más variadas del fenómeno ${ }^{35}$. Parece posible resaltar, a este respecto, una mayor recurrencia fáctica de la hipótesis del aumento del activo y de la disminución del pasivo, como sucede, respectivamente, en los ejemplos habituales de la empresa que potencia sus ventas a partir del uso no autorizado de la imagen ajena y de la persona que invade y disfruta la casa de playa durante el período de viaje de su propietario.

por intromisión, entendido como la ventaja patrimonial obtenida de la explotación no autorizada del bien o derecho ajeno, se basa en la prohibición del enriquecimiento sin causa" (trad. libre del original: "A obrigação de restituir o lucro da intervenção, entendido como a vantagem patrimonial auferida a partir da exploração não autorizada de bem ou direito alheio, fundamenta-se na vedação do enriquecimento sem causa"). Esta conclusión parece ser la tendencia contemporánea del Superior Tribunal de Justicia, como se puede inferir de las siguientes decisiones: STJ, 2. ${ }^{a}$ S., ProAfR. no REsp. 1.552.434/GO, Rel. Min. Paulo de Tarso Sanseverino, Sentencia 14/12/2016; sTu, 3. ${ }^{\text {a }}$ T., REsp. 1.698.701/RJ, Rel. Min. Ricardo Villas Bôas Cueva, Sentencia 2/10/2018. Para un análisis de estas decisiones, véase Fajngold, L., SAlgado, B. y Guerchon, D., "Lucro da intervenção: a disciplina e os julgamentos pioneiros no Superior Tribunal de Justiça", Revista Brasileira de Direito Civil, vol. 21, julio-septiembre, 2019, 182 ss.

34 Con base en semejante línea de entendimiento, la Corte de Justicia del Estado de Río de Janeiro, al considerar la hipótesis fáctica del mal uso de la imagen ajena, determinó la restitución de parte del beneficio obtenido por el interventor, con base en la prohibición del enriquecimiento sin causa (TJERJ, Proceso n. ${ }^{\circ}$ 0008927-17.2014.8.19.0209, 13. ${ }^{\text {a } ~ C . C ., ~ R e l . ~ D e s . ~ F e r n a n d o ~ F e r n a n d y ~ F e r n a n d e s, ~}$ Sentencia 26/10/2016, publ. 31/10/2016). En el análisis de esa decisión se afirma que ella habría establecido "un precedente aparentemente inédito en el ordenamiento jurídico brasileño" (trad. libre). Konder, C. N., "Dificuldades de uma abordagem unitária do lucro da intervenção", cit., ítem 1.

35 En ese sentido véase, por todos, en la doctrina brasileña, NANNI, G. E., Enriquecimento sem causa, 2. ${ }^{\text {a }}$ ed., São Paulo, Saraiva, 2010, 237; en la doctrina portuguesa, CordeIro, A. M., Tratado de direito civil português, vol. II, t. III, Coimbra, Almedina, 2010, 224-226; en la doctrina italiana, SAcCo, R., L'arricchimento ottenuto mediante fatto ingiusto: contributo alla teoria della responsabilità extracontrattuale, Torino, UTET, 1959, reimp., Centro Stampa Università de Camerino, 1980, 196-200; y, en la doctrina francesa, Carbonnier, J., Droit civil, vol. it, Paris, Puf, 2004, 2.436, y Terré, F., Simler, P. y Lequette, Y., Droit civil: les obligations, 11. a ed., Paris, Dalloz, 2013, 1.114-1.115. 
La obtención a costa de otros, a su vez, deriva de la percepción de que la ventaja del interventor deviene, en mayor o menor medida, del bien o del derecho en el que incidió la intervención. Se debe enfatizar, por cierto, que el grado de contribución causal del derecho sobre el cual se intervino y de la conducta del interventor tendrá un impacto directo en la cuantificación de la obligación restitutoria ${ }^{36}$. Finalmente, la falta de causa se indica por el hallazgo de que no existe la autorización legal o comercial para el uso del derecho ajeno, siendo cierto, empero, que la ausencia de un título jurídico formal se debe sopesar con los otros valores relevantes para la delimitación de la (in)justicia del enriquecimiento en cada caso concreto ${ }^{37}$. En realidad, se debe reconocer que la configuración del requisito de la falta de causa que da lugar al surgimiento del deber de restituir el enriquecimiento por intromisión (como, además, de la generalidad de las hipótesis de enriquecimiento sin causa) no se cumple con el simple análisis de la inexistencia de título jurídico en sentido formal y tradicional. Es indispensable, a la inversa, promover el juicio de merecimiento de tutela para que se pueda concluir sobre la justicia o la injusticia del enriquecimiento a la luz de la legalidad constitucional ${ }^{38}$.

\section{Conclusión}

Como hemos visto a lo largo de este breve estudio, el uso del análisis funcional de las obligaciones permite establecer una distinción relevante entre la reparación del daño y la restitución del enriquecimiento sin causa, a cuyo ámbito pertenece el enriquecimiento por intromisión. En resumen, hay una clara diferencia de enfoque: mientras que la prohibición del enriquecimiento sin causa tiene como objetivo la restitución del patrimonio del enriquecido al estado en el que se hallaría en caso de que no se hubiera producido el hecho generador del enriquecimiento sin causa, la responsabilidad civil tiene como función primordial la reparación integral del daño sufrido por la víctima ${ }^{39}$.

De estas distinciones fundamentales surgen, por un lado, la circunstancia de que el enriquecimiento sin causa no requiere ningún empobrecimiento por parte del

36 Véase Lins, T., O lucro da intervenção e o direito à imagem, Rio de Janeiro, Lumen Juris, 2016, 189. En el mismo sentido, véase SiLvA, R. G., "Contornos do enriquecimento sem causa e da responsabilidade civil: estudo a partir da diferença entre lucro da intervenção e lucros cessantes”, Civilistica. com, año 5, n. ${ }^{\circ}$ 2, 2016, 15-16.

37 Al respecto, véase ibíd., 17. Tal comprensión parece explicar la preocupación, encontrada en la doctrina, en el sentido de que el problema del enriquecimiento por intromisión suscitaría mayor atención al requisito de la obtención a costa de otros que al requisito de falta de justa causa (véase, ilustrativamente, LeITÃo, L. M. T. M., O enriquecimento sem causa no direito civil, cit., 894-895).

38 En ese sentido, véase Silva, R. G., Enriquecimento sem causa, cit., 2.3.

39 En ese sentido, véase Pinochet Olave, R. y Concha Machuca, R., "Las prestaciones mutuas en caso de nulidad de contrato", cit., 148; y Terra, A. M. V. y Guedes, G. S. G., "Considerações acerca da exclusão do lucro ilícito do patrimônio do agente ofensor", Revista da Faculdade de Direito da UERJ, n. ${ }^{\circ} 28,2015,21-22$. 
titular del derecho y, por otro lado, el hecho de que la indemnización generalmente ignora eventuales consecuencias patrimoniales positivas de la conducta dañina sobre el patrimonio del propio causador del daño. De ahí la necesidad de enmarcar la cuestión del enriquecimiento por intromisión en el área del enriquecimiento sin causa, siempre y cuando se cumplan los requisitos de la cláusula general del deber de restituir contenida en el artículo 884 c.c. brasileño.

El encuadre sistemático del enriquecimiento por intromisión como una forma de enriquecimiento sin causa tiene consecuencias tanto en lo que respecta al reconocimiento de la posibilidad de acumulación de pretensiones referentes al beneficio obtenido por el interventor y al daño sufrido por el titular del derecho, como en lo que hace a los criterios de cuantificación que deben ser compatibles con el encuadre de la figura en el ámbito del derecho restitutorio. El enriquecimiento por intromisión sigue siendo un tema digno de investigación más profunda en nuestra doctrina, pero tales suposiciones nos permiten corregir algunas posibles desviaciones de ruta, en la que el enriquecimiento por intromisión viene constantemente "ocultado" de modo más o menos deliberado bajo la categoría de lucro cesante, que es una categoría típica del derecho de responsabilidad civil, funcionalmente distinta del derecho restitutorio.

\section{Referencias}

Álvarez-Caperochipi, J. A., El enriquecimiento sin causa, Madrid, Universidad de Santiago de Compostela, 1979.

Amelung, U., Der Schutz der Privatheit im Zivilrecht: Schadenersatz und Gewinnabschöpfung bei Verletzung des Rechts auf Selbstbestimmung über personenbezogene Informationen im deutschen, englischen un US-amerikanischen Recht, Tübingen, Mohr Siebeck, 2002.

BARASSI, L., La teoria generale delle obbligazioni, t. II, 2. ed., Milano, Giuffrè, 1964.

Barbosa, M. M., "Reflexões em torno da responsabilidade civil: teleologia e teleonomologia em debate", Boletim da Faculdade de Direito de Coimbra, vol. 81, 2005 .

Busse, D., Internationales Bereicherungsrecht, Tübingen, Mohr Siebeck, 1998.

Carbonnier, J., Droit civil, vol. II, Paris, PUF, 2004.

Chinchilla Imbett, C. A., “'Contrarius consensus': terminación del contrato por mutuo acuerdo en la experiencia jurídica romana", Revista de Derecho Privado, Universidad Externado de Colombia, n. ${ }^{\circ}$ 28, 2015. 
Chinchilla Imbett, C. A., "El deber de información contractual y sus límites", Revista de Derecho Privado, Universidad Externado de Colombia, n. ${ }^{\circ}$ 21, 2011.

Coelho, F. M. P., O enriquecimento e o dano, Coimbra, Almedina, 1970.

Concha, R., "Nulidad y obligaciones naturales: la obligación de restituir contra el derecho a retener en el código civil de Bello", Revista de Derecho Privado, Universidad Externado de Colombia, n. . 26, 2014.

Cordeiro, A. M., Tratado de direito civil português, vol. II, t. III, Coimbra, Almedina, 2010.

D’Angelo, A., "Sentido actual y condiciones de uso de la disciplina general de las obligaciones", Revista de Derecho Privado, Universidad Externado de Colombia, n. ${ }^{\circ} 20,2011$.

Díez-Picazo, L., Derecho de daños, Madrid, Civitas, 1999.

Espínola, E., Garantia e extinção das obrigações: obrigações solidárias e indivisíveis, Galvão Bruno, F. J. (actualización), Campinas, Bookseller, 2005.

Fajngold, L., Salgado, B. y Guerchon, D., "Lucro da intervenção: a disciplina e os julgamentos pioneiros no Superior Tribunal de Justiça”, Revista Brasileira de Direito Civil, vol. 21, julio-septiembre, 2019.

Ferreira, M. T. T. R., A tutela dos direitos de propriedade industrial pelo enriquecimento sem causa, tesis de máster, Universidad de Lisboa, Lisboa, 2013.

Geldres CAmpos, R., "El enriquecimiento injustificado por intromisión en el derecho ajeno”, Gaceta Civil \& Procesal Civil, n. ${ }^{\circ}$ 54, 2017.

Giannotte, C., “Arricchimento senza causa”, en Cendon, P. (ed.), Trattato di diritto civile: titoli di credito, gestione di affari, ripetizione di indebito, arricchimento, Milano, Giuffrè, 2014.

Gomes, J. M. V., O conceito de enriquecimento, o enriquecimento forçado e os vários paradigmas do enriquecimento sem causa, Porto, Universidade Católica Portuguesa, 1998.

Hinestrosa, F., "Devenir del derecho de daños", Revista de Derecho Privado, Universidad Externado de Colombia, n. . 32, 2017. 
Hinestrosa, F., "Notas sobre la responsabilidad por incumplimiento de las obligaciones", Revista de Derecho Privado, Universidad Externado de Colombia, n. ${ }^{\circ}$ 36, 2019.

Konder, C. N., "Dificuldades de uma abordagem unitária do lucro da intervenção", Revista de Direito Civil Contemporâneo, vol. 13, octubre-diciembre, 2017.

Konder, C. N. y SAAR, P., “A relativização do duplo limite e da subsidiariedade nas ações por enriquecimento sem causa”, en Tepedino, G., Teixeira, A. C. B. y Almeida, V. (coords.), Da dogmática à efetividade do direito civil. Anais do Congresso Internacional de Direito Civil Constitucional - IV Congresso do IBDCivil, Belo Horizonte, Fórum, 2017.

Larenz, K., Derecho de obligaciones, t. I, J. Santos Briz (trad.), Madrid, Revista de Derecho Privado, 1958.

LeITÃo, L. M. T. M., O enriquecimento sem causa no direito civil: estudo dogmático sobre a viabilidade da configuração unitária do instituto, face à contraposição entre as diferentes categorias de enriquecimento sem causa, Lisboa, Centro de Estudos Fiscais, 1996.

Lins, T., O lucro da intervenção e o direito à imagem, Rio de Janeiro, Lumen Juris, 2016.

Michelon Jr., C., Direito restituitório: enriquecimento sem causa, pagamento indevido, gestão de negócios, São Paulo, Revista dos Tribunais, 2007.

Miragem, B., "Pretensão de repetição de indébito do consumidor e sua inserção nas categorias gerais do direito privado: comentário à Súmula 322 do STJ", Revista de Direito do Consumidor, vol. 79, julio-septiembre, 2011.

Nanni, G. E., Enriquecimento sem causa, 2. a ed., São Paulo, Saraiva, 2010.

Noronha, F., Direito das obrigações, 4. a ed., São Paulo, Saraiva, 2013.

Perlingieri, P., O direito civil na legalidade constitucional, M. C. De Cicco (trad.), Rio de Janeiro, Renovar, 2008.

Pinochet Olave, R. y Concha Machuca, R., "Las prestaciones mutuas en caso de nulidad de contrato: carácter indemnizatorio o restitutorio en el derecho civil chileno", Revista de Derecho Privado, Universidad Externado de Colombia, n. ${ }^{\circ}$ $28,2015$. 
Rosenvald, N., A responsabilidade civil pelo ilícito lucrativo: o disgorgement e a indenização restitutória, Salvador, JusPodivm, 2019.

Rosenvald, N., “As fronteiras entre a restituição do lucro ilícito e o enriquecimento por intromissão", Revista de Direito da Responsabilidade, año 1, 2019.

SAcCo, R., L'arricchimento ottenuto mediante fatto ingiusto: contributo alla teoria della responsabilità extracontrattuale, Torino, UTET, 1959, reimp., Università de Camerino, 1980.

SANDOval, D. "Reparación integral y responsabilidad civil: el concepto de reparación integral y su vigencia en los daños extrapatrimoniales a la persona como garantía de los derechos de las víctimas", Revista de Derecho Privado, Universidad Externado de Colombia, n. ${ }^{\circ}$ 25, 2013.

Schreiber, A. y Silva, R. G., "Aspectos relevantes para a sistematização do lucro da intervenção no direito brasileiro", Pensar, vol. 23, n. . 4, 2018.

Schulz, F., "System der Rechte auf den Eingriffserwerb", Archiv für die civilistische Praxis, vol. 105, t. 1, 1909.

Silva, R. G., "Contornos do enriquecimento sem causa e da responsabilidade civil: estudo a partir da diferença entre lucro da intervenção e lucros cessantes", Civilistica.com, año 5, n. $.^{\circ} 2,2016$.

Silva, R. G., Enriquecimento sem causa: as obrigações restitutórias no direito civil, São Paulo, Thomson Reuters Brasil, 2018.

Silva, R. G., "Novas perspectivas da exceção de contrato não cumprido: repercussões da boa-fé objetiva sobre o sinalagma contratual", Revista de Direito Privado, año 18, n. $^{\circ} 78,2017$.

Terra, A. M. V. y Guedes, G. S. G., "Considerações acerca da exclusão do lucro ilícito do patrimônio do agente ofensor", Revista da Faculdade de Direito da UERJ, n. ${ }^{\circ} 28,2015$.

Terré, F., Simler, P. y Lequette, Y., Droit civil: les obligations, 11. a ed., Paris, Dalloz, 2013.

Uribe, R. M. y Wilson, C. P., "Las restituciones consecutivas a la nulidad o resolución en los contratos de bienes muebles”, Ius et Praxis, año 24, n. ${ }^{\circ}$ 1, 2018. 